\title{
Low level of polymorphism in two putative NPR1 homologs in the Vitaceae family
}

\author{
Karine Bergeault ${ }^{*}$, Christophe Bertsch ${ }^{1}$, Didier Merdinoglu², Bernard Walter ${ }^{1}$
}

\begin{abstract}
Background: Grapevine is subjected to numerous pests and diseases resulting in the use of phytochemicals in large quantities. The will to decrease the use of phytochemicals leads to attempts to find alternative strategies, implying knowledge of defence mechanisms. Numerous studies have led to the identification of signalling pathways and regulatory elements involved in defence in various plant species. Nonexpressor of Pathogenesis Related 1 (NPR1) is an important regulatory component of systemic acquired resistance (SAR) in Arabidopsis thaliana.

Results: Two putative homologs of NPR1 gene were found in the two sequenced grapevine genomes available in the Genoscope database for line 40024 and in the IASMA database for Pinot noir ENTAV 115. We named these two NPR1 genes of Vitis vinifera: VVNPR1.1 and VVNPR1.2. A PCR-based strategy with primers designed on exons was used to successfully amplify NPR1 gene fragments from different Vitaceae accessions. Sequence analyses show that NPR1.1 and NPR1.2 are highly conserved among the different accessions not only $V$. vinifera cultivars but also other species. We report nucleotide polymorphisms in NPR1.1 and NPR1.2 from fifteen accessions belonging to the Vitaceae family. The ratio of nonsynonymous to synonymous nucleotide substitutions determines the evolutionary pressures acting on the Vitaceae NPR1 genes. These genes appear to be experiencing purifying selection. In some of the species we have analysed one of the two alleles of NPR1.1 contains a premature stop codon. The deduced amino acid sequences share structural features with known NPR1-like proteins: ankyrin repeats, BTB/POZ domains, nuclear localization signature and cysteines. Phylogenetic analyses of deduced amino acid sequences show that VVNPR1.1 belongs to a first group of NPR1 proteins known as positive regulators of SAR and VVNPR1.2 belongs to a second group of NPR1 proteins whose principal members are AtNPR3 and AtNPR4 defined as negative regulators of SAR.
\end{abstract}

Conclusion: Our study shows that NPR1.1 and NPR1.2 are highly conserved among different accessions in the Vitaceae family. VVNPR1.1 and VVNPR1.2 are phylogenetically closer to the group of positive or negative SAR regulators respectively.

Reviewers: This article was reviewed by Fyodor Kondrashov, Purificación López-García and George V. Shpakovski.

\section{Background}

The Vitaceae family consists of approximately 700 species classified in 14 genera. Ampelopsis and Parthenocissus are two genera related to each other. The genus Vitis has been divided into two distinct sections called Euvitis and Muscadinia [1]. These two sections can be differentiated not only on morphological and anatomical appearance but also on chromosome number. Muscadinia have $2 \mathrm{n}=40$ chromosomes while Euvitis have only

\footnotetext{
* Correspondence: karine.bergeault@uha.fr

'Laboratoire Vigne, Biotechnologies \& Environnement, Université de Haute Alsace, 33 rue de Herrlisheim, 68000 Colmar, France
}

$2 \mathrm{n}=38$ [2]. Vitis vinifera, as well as several other species and hybrids of Vitis, are well known economically for grapes, wine and raisins productions. Grape and their derivatives have an increasing worldwide market [3]. Vineyard is constantly subjected to numerous stresses due to climatic conditions, farming techniques, mineral deficiency or pathogens. Vineyards are threatened by numerous viruses, bacteria and fungi. This situation leads wine growers to use chemicals in large quantities.

The stimulation of grapevine's own defences could be an alternative strategy to phytochemicals. Numerous

\section{Biomed Central}


studies have led to the identification of several plant genes involved in defence mechanisms and especially in signal transduction pathways [4]. Nonexpressor of $P R 1$ (NPR1) gene of Arabidopsis thaliana is an important regulatory component of systemic acquired resistance (SAR) [5-7]. SAR is a plant immune response that is triggered after local infection with pathogens [8-10]. The onset of SAR requires the accumulation of salicylic acid (SA) and the coordinated expression of pathogenesis-related (PR) genes [7]. Besides SA-mediated SAR, other pathways are involved in plant defence systems, namely ISR (induced systemic resistance) and jasmonic acid (JA)-mediated pathways. The SAR and ISR pathways are independent but have an overlapping requirement for NPR1 [11]. When SA and JA are applied together to leaves, the presence of SA inhibits JA synthesis and signalling. This inhibition is alleviated in the npr1 mutant, indicating that NPR1 is part of the crosstalk control between signalling pathways [12]. NPR1 is a positive regulator of the plant defence response and its mechanism of action is well characterized.

The NPR1 protein localizes both to the cytoplasm and the nucleus [13]. Upon pathogen attack, accumulation of SA causes a decrease in cellular reduction potential, leading to the conversion of NPR1 from inactive oligomers into active monomers that enter the nucleus and interact differentially with TGA proteins which are basic-region leucine zipper (bZIP) transcription factors. This interaction stimulates the DNA binding activity of TGA factors to SA-responsive elements in the promoter of pathogenesis-related genes $[8,14,15]$. The Arabidopsis thaliana genome contains six NPR1-related genes [16] (called AtNPR1 to AtNPR6), whose deduced proteins all share the Broad Complex, Tramtrack and Bric a brac/ Pox virus and Zinc finger (BTB/POZ) domain and the Ankyrin Repeat Domain (ARD). According to Mou et al. (2003) [15], AtNPR1 and NPR1-like proteins from four plant species contain ten conserved cysteines. Cys 82 and Cys 216 are essential for keeping NPR1 in the cytoplasm [15]. NPR1 genes have been found in genomes of various species such as rice $[17,18]$, Indian mustard [19], apple [20] and cotton [21]. Overexpression of AtNPR1 in Arabidopsis thaliana, rice, tomato and wheat enhances fungal and bacterial resistance $[17,20,22-27]$ through elevated expression of $P R$ genes $[22,25]$.

In plants, molecular diversity was first studied based on the existence of mutational events. Detection of single nucleotide polymorphisms (SNPs) allows the analysis of sequence differences between alleles. Nucleotide diversity reflects the combined history of selection, migration, recombination and mating systems experienced by species. Nucleotide diversity is one source of phenotypic variation [28]. SNPs have been characterized in crop plant genomes such as maize, sugarbeet, barley, soybean, wheat, rice and grapevine [29]. As the grapevine is propagated vegetatively, its genome has a higher probability to accumulate large deletions, insertions, inversions or other events which may differentiate the two pairs of chromosomes.

In the present study, a PCR-based strategy with primers designed on exons was used to successfully amplify NPR1 exons. A phylogenetic tree was used to analyse the relationship of NPR1 proteins from Arabidopsis thaliana and homologs from various plant species. Analysis of sequence mutations was done to study the polymorphism of NPR1 in fifteen accessions of the Vitaceae family. To examine the evolutionary pressures acting on the NPR1.1 and NPR1.2, the ratio of nonsynonymous (replacement) to synonymous (silent substitution) nucleotides was determined.

\section{Results and discussion}

Putative homologs of AtNPR1 in grapevine: VvNPR1.1 and VvNPR1.2

We named $V v N P R 1.1$ and $V v N P R 1.2$ two putative homologs of the AtNPR1 gene from the grapevine genome sequences published by the French-Italian Public Consortium for Grapevine Genome (line 40024) and by the Istituto Agrario Di San Michele All'Adige (Vitis vinifera Pinot noir ENTAV 115). Line 40024 [30] is highly homozygous and Pinot noir ENTAV 115 [31] is heterozygous. No additional member of the NPR1 gene family was found in NCBI and ESTAP databases after blast and key words research. The intron-exon structure in NPR1.1 and NPR1.2 from the Vitaceae accessions was the same as in AtNPR1: four exons and three introns, except for Ampelopsis japonica where intron 3 is missing. The complete cDNA is $1,755 \mathrm{bp}$ for $V v N P R 1.1$ and 1,764 bp for $V v N P R 1.2$. The deduced proteins have 584 and 587 amino acids, respectively and they share structural features with known NPR1 proteins which are highly conserved across many species: ankyrin repeats in the middle of the protein (ARD), the N-terminal BTB/ POZ domains, the $\mathrm{C}$-terminal nuclear localization signature (NLS) [32] and nine among ten conserved cysteines described by Mou et al. (2003) [15] (Figure 1). This suggests that VvNPR1 may interact with other proteins, as previously described in Arabidospsis thaliana [13,33-36].

The amino acids 61-184 of VvNPR1.1 and 64-190 of VvNPR1.2 show similarity to the BTB/POZ motif. The amino acids 259-318 and 322-351 of VvNPR1.1 and amino acids 296-326 and 330-359 of VvNPR1.2 reveal respectively three and two highly conserved ankyrin repeats (Figure 1). The deduced amino acid sequences of VvNPR1.1 and VvNPR1.2 show 43\% identity. VvNPR1.1 and VvNPR1.2, respectively, show 52\% and 37\% identity with AtNPR1. Three phylogenic groups 

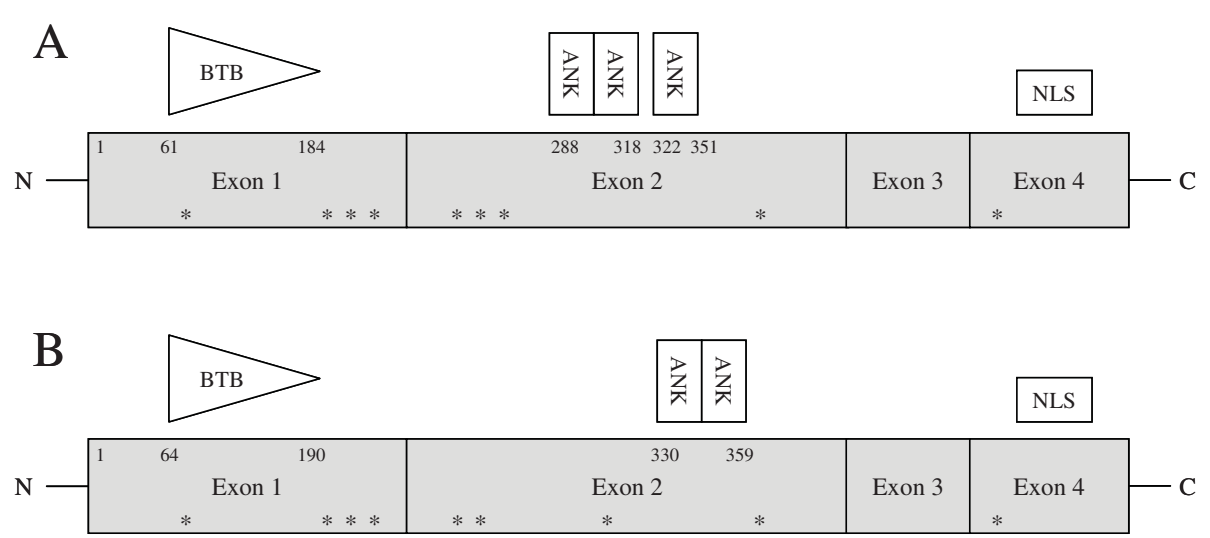

Figure 1 Schematic representation of VvNPR1.1 (A) and VvNPR1.2 (B). The positions of the BTB/POZ, ankyrin repeat domains, nuclear localization signature and conserved cysteine residues represented by stars are shown. Numbers represent amino acid positions.

have been described in the AtNPR1 protein family by Hepworth et al. (2005) [37] (Figure 2). These authors stated that branching pattern suggests that members in each group may have similar functions. VvNPR1.1 is close to AtNPR1 and AtNPR2 in the first group. VvNPR1.2 is with AtNPR3 and AtNPR4 in the second group. AtNPR5 and AtNPR6 present high homology with Blade-on-petiole 1 and 2 of A. thaliana (BOP1 and BOP2) which involved in some aspects of morphogenesis and leaf/flower development [37]. A putative Bladeon-petiole gene which we named Vitis vinifera $B O P$ $(V v B O P)$ was identified in the Genoscope database. VvBOP is closely related to AtNPR5 and AtNPR6 and can be involved in morphogenesis and leaf/flower development, like AtNPR5 and AtNPR6 (Figure 2) $[6,16,19,20,23,30,38-40]$.

\section{Purifying selection for Vitaceae NPR1.1 and Vitaceae NPR1.2}

Sequence data for fifteen accessions belonging to the Vitaceae family (Figure 3) were obtained from NPR1 fragments amplified using PCR primers. Identification of polymorphic sites was based on two alleles sequenced. Figures 4 and 5 show the distribution of SNPs along the four exons of NPR1.1 and NPR1.2 respectively, in Ampelopsis japonica, Muscadinia rotundifolia, Parthenocissus quinquefolia and five American Vitis species and in six $V$. vinifera cultivars (Gouais blanc, Muscat reine des vignes, Cabernet Sauvignon, Riesling, Pinot noir, Gewurztraminer). The SNPs are not evenly distributed. NPR1.1 exon 3 and the four NPR1.2 exons have a low SNP rate ( $4 \%$ to $5.4 \%$ SNPs per exon), in comparison with NPR1.1 exons 1,2 and 4 (7.2\% to 8.4\% SNPs per exon). Globally, NPR1.1 is more polymorphic than NPR1.2. In the six $V$. vinifera cultivars, SNP rate is lower than $2.5 \%$ (0.1\% in $V v N P R 1.1$ exon 2 to $2.5 \%$ in $V v N P R 1.2$ exon 3$)$ and $4.2 \%$ in $V v N P R 1.2$ exon 4 . In the six $V$. vinifera

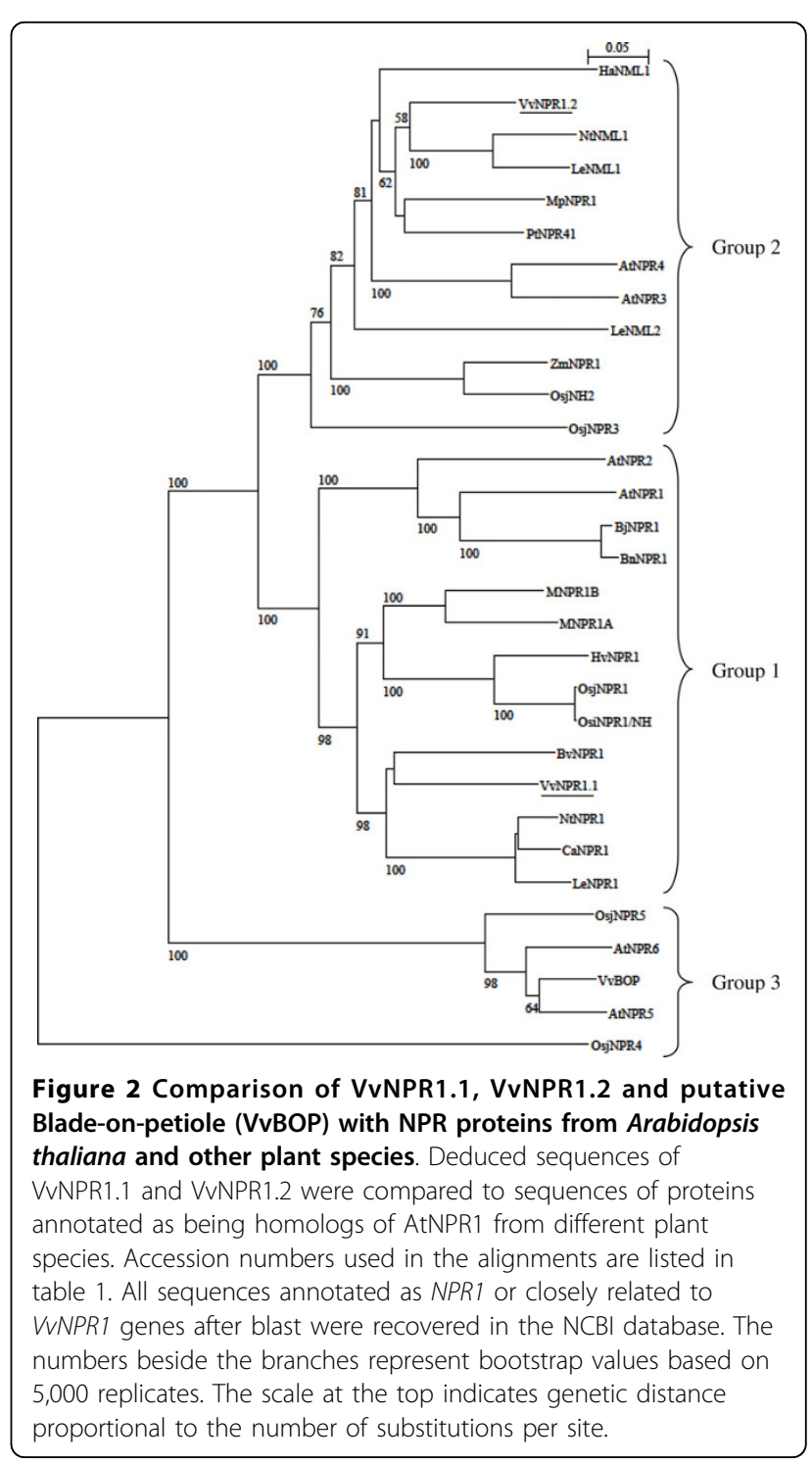




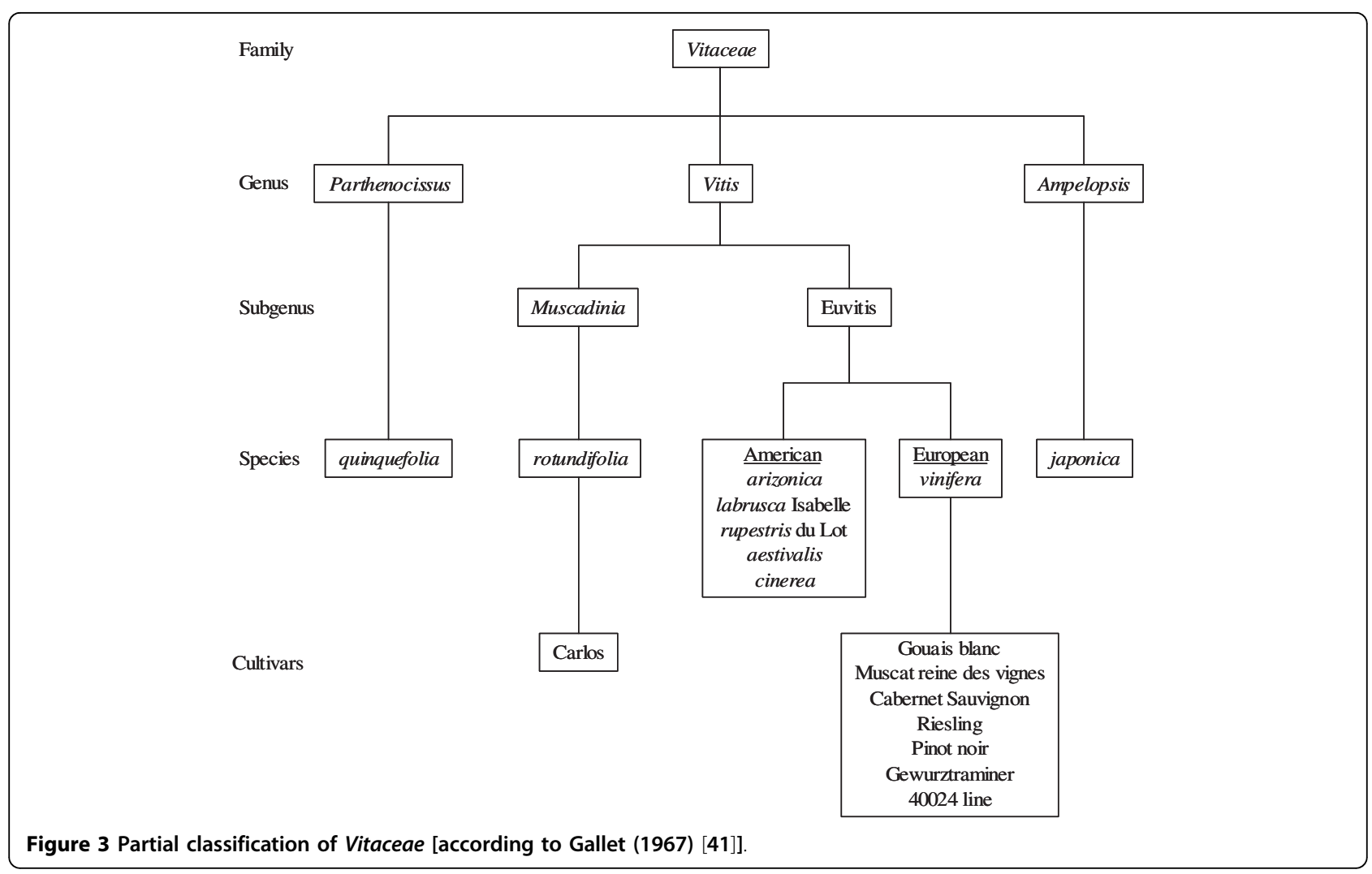

cultivars, SNP rate in introns (about 2\%, data not shown) was not significantly different from SNP rate in exons [41].

\section{NPR1.1}

Polymorphisms in exon 1 and exon 4 of NPR1.1 were identified by silent substitutions at positions 23, 31, 515 and a missense substitution at position 576. A threonine codon present in all the other accessions changed in an asparagine codon in line 40024. Missense substitutions in the BTB/POZ domain cause protein modifications (Figure 1). It is likely that substitutions have important consequences for the function of the $\mathrm{BTB} / \mathrm{POZ}$ domain and perhaps its regulation. In fact, the $\mathrm{BTB} / \mathrm{POZ}$ domain is an evolutionarily conserved protein-protein interaction motif [42]. A mutation in this region results in the loss of NPR1 function and affects protein-protein interaction [6,7]. A heterozygous zone, observed in Ampelopsis japonica, Muscadinia rotundifolia, Parthenocissus quinquefolia, V. cinerea, $V$. aestivalis, $V$. rupestris, $V$. arizonica and $V$. vinifera Cabernet Sauvignon, at the beginning of NPR1.1 exon 3, shows a nucleotide substitution in a glycine codon (GGA) which introduces a premature stop codon (TGA) in the central part of the protein. These results suggest that one of the two NPR1.1 alleles generates a truncated protein (427 aa) derived from translation of only exon 1 and 2 . As a result, the truncated protein does not retain one of the conserved cysteines, but contains all of the protein-protein interaction domains. The truncated protein VvNPR1.1 should be functional because it possesses the interaction domain and nine of ten conserved cysteines. The missing cysteine is not essential for the nuclear localization [15]. Nonsense substitutions that generate a premature translational termination signal should reduce the steady-state accumulation of the corresponding mRNA [43]. No readthrough mechanism have been described until now in plants and nonsense substitutions are not enough to stop the translation since the second allele can be entirely expressed. Alleles rendered nonfunctional due to mutations causing frame shifts and/or premature stop codons were observed for five defence response loci (EDS5, ESP, ETR1, EDS1 and PAD4) in A. thaliana [44]. There is no evidence for non-functional AtNPR1 alleles but it could be different for $V v N P R 1.1$. The ankyrin repeat domain of AtNPR1 are necessary and sufficient for the interaction with members of the TGA family of transcription factors, although high-affinity interactions also require the N-terminal one third of NPR1 [13,35,36].

NPR1.2

A deletion of 3 amino acids (amino acids 17 to 19) and a supplementary pattern of 6 amino acids were found in 

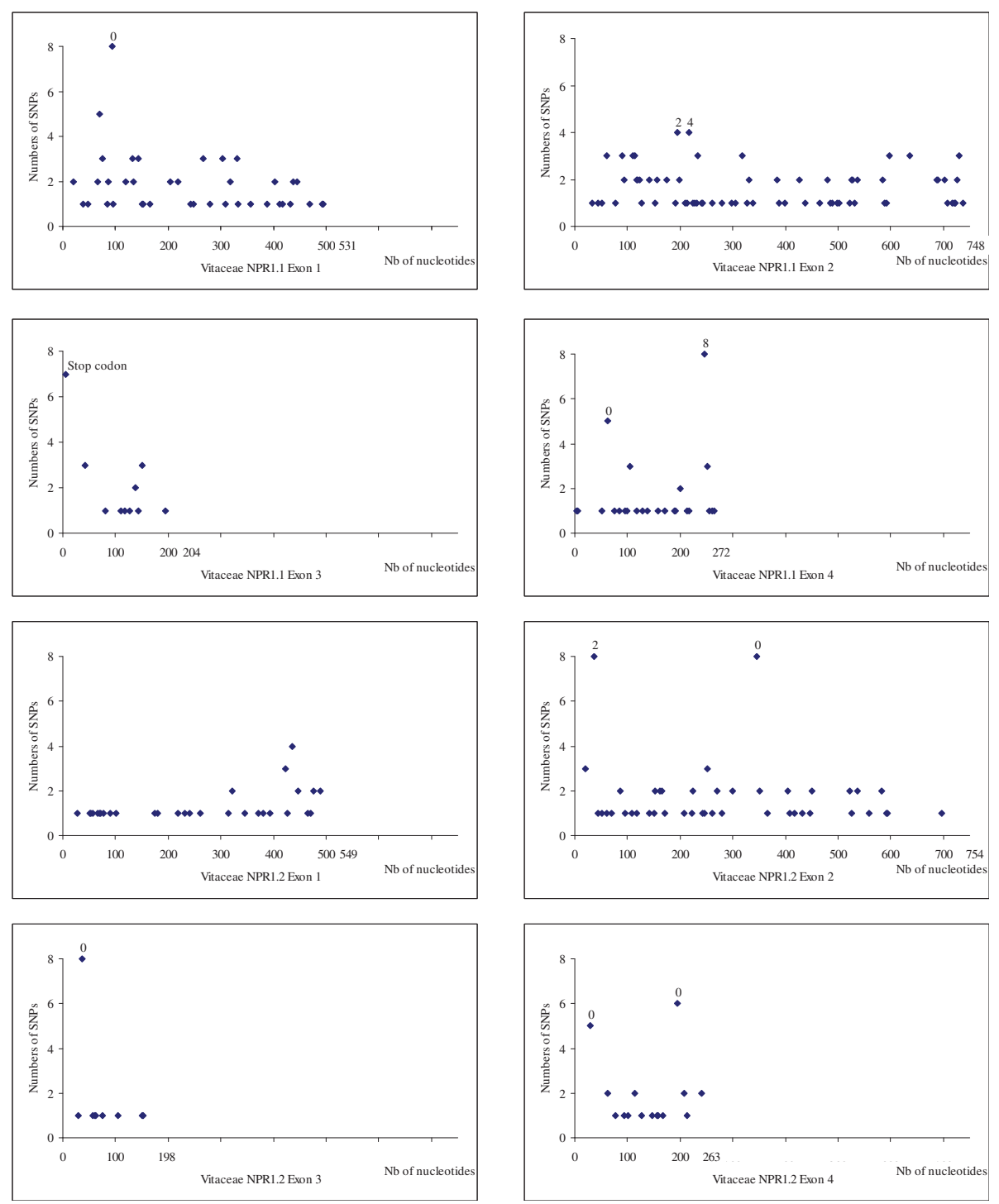

Figure 4 Distribution of SNPs in NPR1.1 and NPR1.2 along exons 1 to 4. From Ampelopsis japonica, Muscadinia rotundifolia Carlos, Parthenocissus quinquefolia and five American Vitis species. The horizontal scale indicates the nucleotide number. The vertical scale indicates the number of SNPs counted at each position among the eight species in comparison to line 40024. Numbers represent missense substitutions.

exon 4 of Ampelopsis japonica NPR1.2. This supplementary pattern is not a preserved protein pattern according to web-based SMART program.

Polymorphisms in exons 2, 3 and 4 of NPR1.2 were identified by silent substitutions at positions 298,446 and 565 and a change at position 195 from a leucine codon into a valine in Ampelopsis japonica and Parthenocissus quinquefolia.

According to Bakker et al. (2008) [44], there are three distinguished evolutionary scenarios for selection: (1) long-term balancing selection, where a gene may have highly diverged alleles at intermediate frequencies and a high level of silent polymorphism, (2) positive selection of a favorable allele, which can generate a locus with few, relatively young alleles with extended haplotypes and (3) purifying selection or functional constraint, which leads to low levels of nonsynonymous polymorphism and a commensurately low rate of divergence between species.

From our results, the ratio of nonsynonymous to synonymous nucleotide substitutions $(\mathrm{Ka} / \mathrm{Ks})$ relating influence of selection is smaller than 1 in both genes (0.84 in NPR1.1 and 0.44 in NPR1.2). These results suggest a purifying selection against substitutions that would result in amino acid replacements. In NPR1.2, the ratio is also lower than 1 for the four exons taken independently (0.34 to 0.68$)$. The comparison of selected clones from fifteen accessions belonging to the Vitaceae 

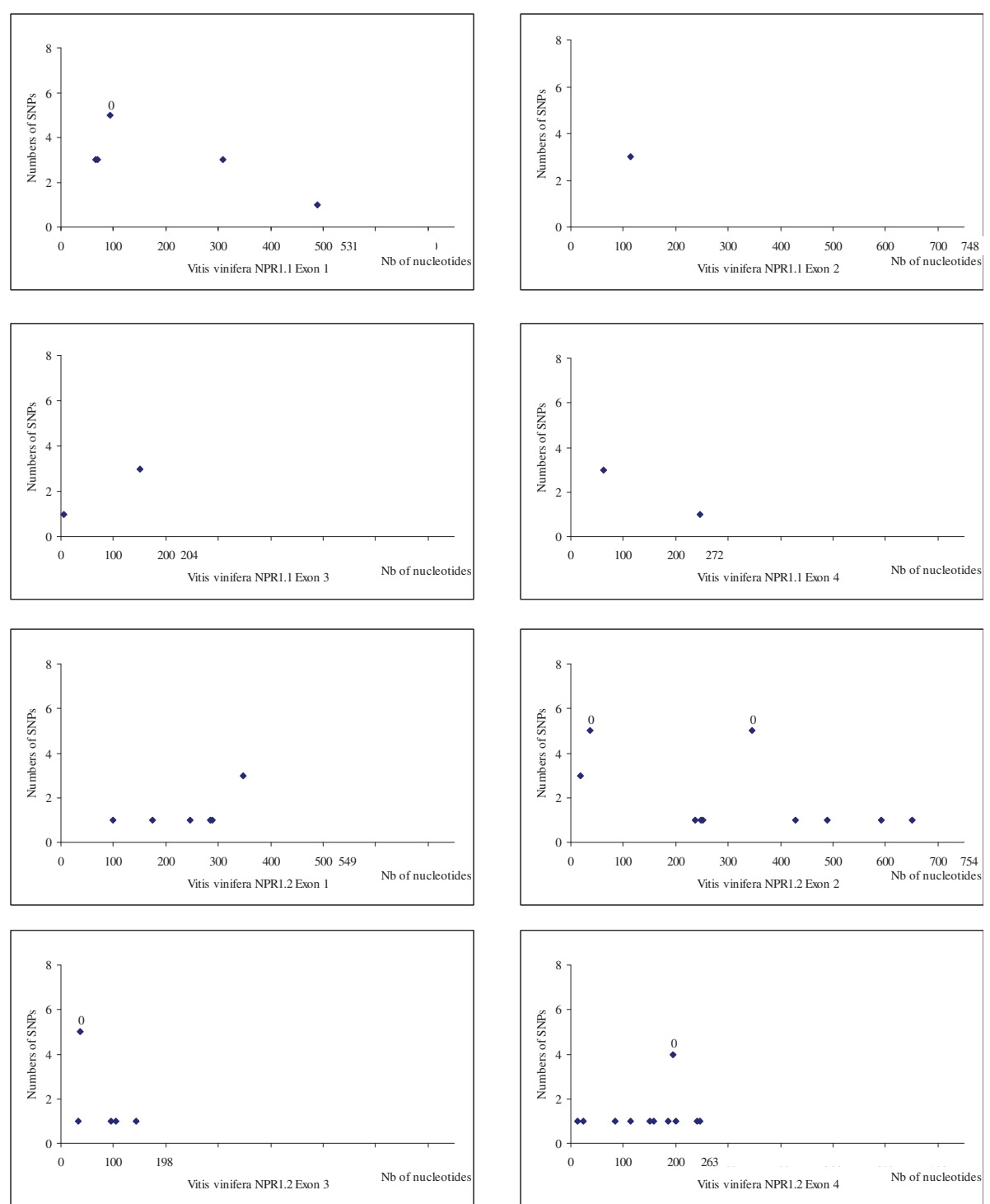

Figure 5 Distribution of SNPs in NPR1.1 and NPR1.2 along exons 1 to 4. From six Vitis vinifera cultivars (Gouais blanc, Muscat reine des vignes, Cabernet Sauvignon, Riesling, Pinot noir, Gewurztraminer). The horizontal scale indicates the nucleotide number. The vertical scale indicates the number of SNPs counted at each position among the eight species in comparison to line 40024 . Numbers represent missense substitutions.

family revealed a high homology for the two genes. The polymorphism data in NPR1.1 and NPR1.2 indicate purifying selection and sequence conservation. Generally, the defence response genes tend to maintain lower levels of diversity. The majority of defence response genes appear to be experiencing purifying selection [44]. In general, defence response genes do not appear to be under balancing selection but strong evidence of balancing selection was detected at AtNPR1 [44,45]. Our results show that NPR1.1 and NPR1.2 are highly conserved under strong purifying selection and do not vary much from accession to accession, indicating that mutations probably have deleterious consequences. Purifying selection results in the reduction of genetic variation through the elimination of maladjusted alleles and consequently of the mutations that caused the maladjustment. These contradictory results may be related to the fact that $A$. thaliana multiplies by sexual reproduction while grapevine by vegetative propagation.

\section{Functional hypothesis: two types of regulations by NPR1-} like genes?

The complete sequence of putative homologs of the AtNPR1 gene family is known in various species (Table 1 ). According to the phylogenetic tree (Figure 2), three groups of NPR genes can be distinguished. VvNPR1.1 is 
in the same group as NPR1 from sugar beet, tobacco, sweet pepper and tomato as also AtNPR1 and AtNPR2 from Arabidopsis and rice OsiNPR1/NH1. From the ten cysteines described as conserved in AtNPR1 and NPR1like proteins, only eight are conserved in all the Vitaceae accessions we have analyzed, but the two cysteines essential for oligomer formation are present [15] (Figure 6). Sequence similarities, conservation of functional sites and cysteines suggest that VvNPR1.1 could have functions similar to that of AtNPR1 as a positive regulator of SAR. Nevertheless, functions of a limited number of NPR1 homologs have been studied. The expression of BjNPR1, MNPR1A and MNPR1B is induced by SA or MeJA treatment. BjNPR1-GFP fusion protein is localized to the nucleus following SA treatment. MNPR1A and $M N P R 1 B$ increase PR gene expression [38]. Overexpression of BnNPR1 from canola and OsiNPR1/NH1 in rice complement the nprl mutations and enhance resistance $[23,46,47]$. The NPR1 proteins in the first group could be activated during potential redox modifications induced by SA or various pathogenic conditions and show a similar regulation across different species.

VvNPR1.2 is grouped with NtNML1 and LeNML1 as also AtNPR3 and AtNPR4 which have been described as negative regulators of SAR (Figure 2) [34]. Only five of the ten cysteine residues are conserved in the proteins from the group 2. Cysteine 216 which is essential for oligomerization in AtNPR1 is absent from all the NPR1 in group 2. The absence of cysteine residue 216 (Figure 7) suggests that VvNPR1.2 should be differently regulated, as observed for AtNPR3 and AtNPR4. AtNPR3 and AtNPR4 perform overlapping functions and that loss of the function in npr3 npr4 double mutant leads to much higher $P R-1$ expression and enhanced resistance [34]. It is plausible that AtNPR3 and AtNPR4 negatively regulate $P R-1$ expression and pathogen resistance [34]. Inactivating both AtNPR3 and AtNPR4 leads to activation of TGA and expression of PR genes [34]. AtNPR3 and AtNPR4 would be negative regulators of plant defence responses [34]. A contradictory result has been reported with MpNPR1-1 which is induced by the SAR and its overexpression increases the resistance of apple to pathogens, suggesting that MpNPR1 may act as a positive regulator despite the absence of cysteine 216 [20]. Therefore, phylogenetic analysis is not sufficient to predict a positive or negative control of defence responses for $V v N P R 1.2$.

\section{Conclusions}

Homologs of the Arabidopsis NPR1 gene have now been isolated from numerous other plant species. Our study with Genoscope annotations provides the existence of a possible NPR1 gene family in Vitaceae. VvNPR1.1 and $V v N P R 1.2$ genes have four exons and three introns. The

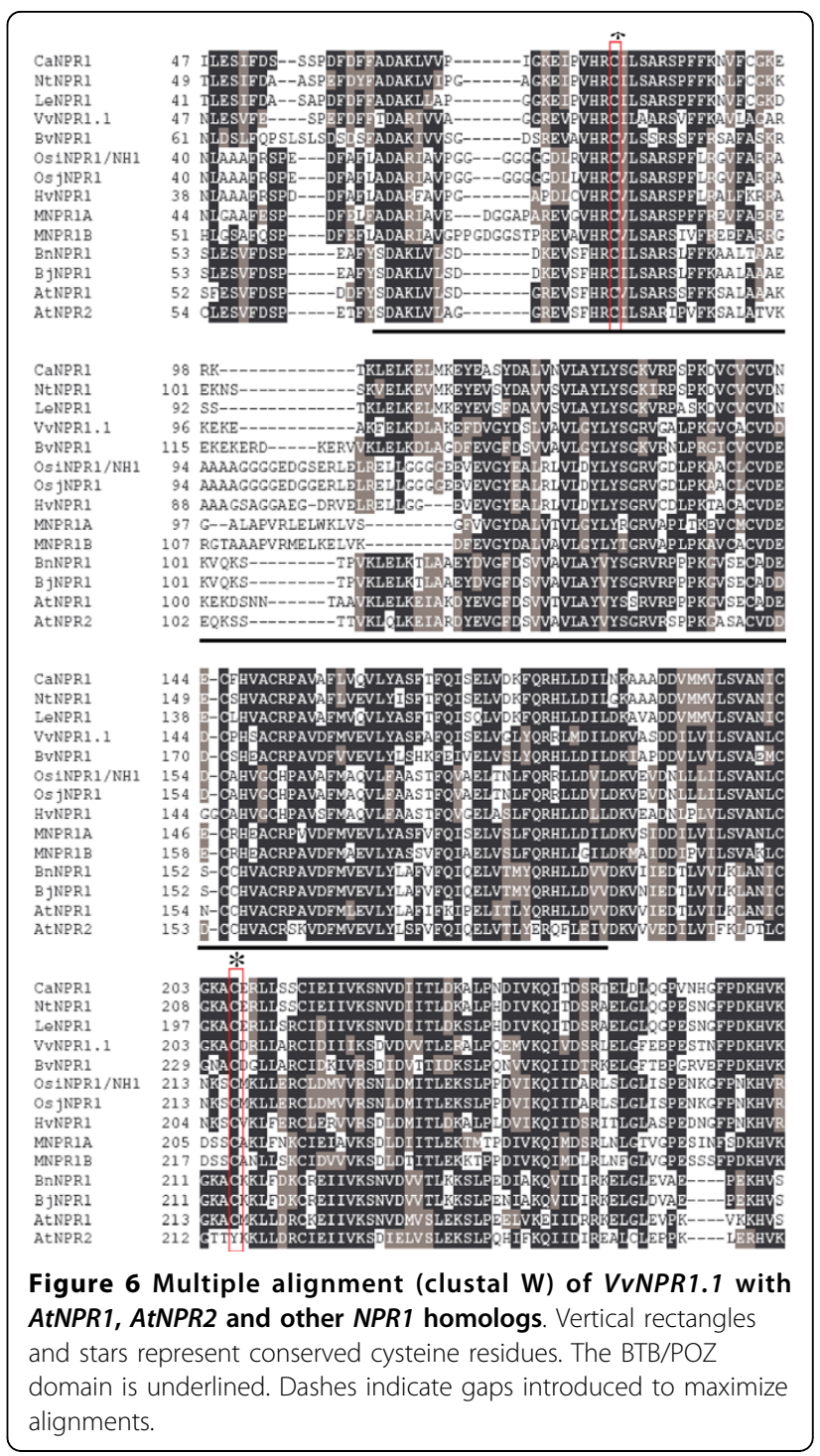

deduced amino acid sequences show $52 \%$ and $37 \%$ identity to AtNPR1, and all three functional domains identified in A. thaliana NPR1 are conserved in the Vitaceae NPR1. The polymorphism on these two genes is in favour of purifying selection. Two Vitis vinifera NPR1-like proteins are separated in two of the three groups described by Hepworth et al. (2005) [37]. We have shown that the VvNPR1.1 is related to a first NPR1 group of positive regulators of SAR and VvNPR1.2 is related to a second NPR1 group whose principal members would be negative regulators of SAR, AtNPR3 and AtNPR4.

\section{Methods}

Plant material and DNA extraction

Ampelopsis japonica, Muscadinia rotundifolia cv. Carlos, Parthenocissus quinquefolia, five American Vitis species (arizonica, labrusca Isabelle, rupestris du Lot, aestivalis 
Table 1 Proteins from the NPR1 family in different plants species

\begin{tabular}{|c|c|c|}
\hline Taxon & GenBank Accession Numbers & References \\
\hline \multicolumn{3}{|l|}{$\overline{\text { Dicots }}$} \\
\hline Arabidopsis thaliana (AtNPR1) & AT1G64280 & Cao et al., 1997 [6] \\
\hline Arabidopsis thaliana NPR2 (AtNPR2) & NM_118745 & Liu et al., 2005 [16] \\
\hline Arabidopsis thaliana NPR3 (AtNPR3) & NM_123879 & \\
\hline Arabidopsis thaliana NPR4 (AtNPR4) & NM_118086 & \\
\hline Arabidopsis thaliana NPR5 (AtNPR5) & NM_129700 & \\
\hline Arabidopsis thaliana NPR6 (AtNPR1) & NM_115572 & \\
\hline Beta vulgaris (BVNPR1) & AY640381 & Meur et al., 2006 [19] \\
\hline Brassica juncea (BjNPR1) & AY667498 & \\
\hline Brassica napus (BnNPR1) & AF527176 & \\
\hline Capsicum annuum (CaNPR1) & ABG38308 & \\
\hline Helianthus annuus NIM1-like protein 1 (HaNML1) & AY640383 & \\
\hline Hordeum vulgare (HvNPR1) & AM050559 & \\
\hline Lycopersicon esculentum (LeNPR1) & AY640378 & \\
\hline Lycopersicon esculentum NIM1-like protein 1 (LeNML1) & AY640379 & \\
\hline Lycopersicon esculentum NIM1-like protein 2 (LeNML2) & AY640380 & \\
\hline Malus $\times$ domestica cultivar (MpNPR1) & EU624123 & Malnoy et al., 2007 [20] \\
\hline Musa acuminata (MNPRIA) & DQ925843 & Endah et al., 2008 [38] \\
\hline Musa acuminata (MNPR1B) & EF137717 & Zwicker et al., 2007 [39] \\
\hline Nicotiana tabacum (NtNPR1) & DQ837218 & Jaillon et al., 2007 [30] \\
\hline Nicotiana tabacum NIM1-like protein 1 (NtNML1) & AY640382 & $\begin{array}{l}\text { Jaillon et al., } 2007 \text { [30] } \\
\text { Jaillon et al., } 2007 \text { [30] }\end{array}$ \\
\hline Populus trichocarpa (PtNPR41) & DQ481233 & \\
\hline Vitis vinifera NPR1.1 (VvNPR1.1) & CAO65332 & \\
\hline Vitis vinifera NPR1.2 (VVNPR1.2) & CAN67078 & \\
\hline Vitis vinifera $B O P(V v B O P)$ & CAO23333 & \\
\hline \multicolumn{3}{|l|}{ Monocots } \\
\hline Oryza sativa indica (OsiNPR1/NH1) & & Chern et al., 2005 [23] \\
\hline Oryza sativa japonica (OsjNPR1) & & Ohyanagi et al., 2006 [40] \\
\hline \multicolumn{3}{|l|}{ Oryza sativa japonica (OsjNH2) } \\
\hline \multicolumn{3}{|l|}{ Oryza sativa japonica (OsjNPR3) } \\
\hline \multicolumn{3}{|l|}{ Oryza sativa japonica (OsjNPR4) } \\
\hline \multicolumn{3}{|l|}{ Oryza sativa japonica (OsjNPR5) } \\
\hline Zea mays (ZmNPR1) & & \\
\hline
\end{tabular}

and cinerea), six Vitis vinifera cultivars (Gouais blanc, Muscat reine des vignes, Cabernet Sauvignon clone 169, Riesling clone 49, Pinot noir clone 162, Gewurztraminer clone 46) and V. vinifera inbred line 40024 [48] [derived from Pinot noir, and bred close to full homozygosity (estimated at about 93\%) by successive selfings [30] were used. The reference sequence used for SNP analysis was from line 40024 [48]. Classification of the various accessions used in this study is schematized in figure 3 .

40024 genomic DNA was extracted using DNeasy ${ }^{\oplus}$ Plant Mini Kit (Qiagen, Courtaboeuf, France) following the manufacturer's recommendations and the other DNAs were a generous gift from Dr F. Pelsy (INRA, Colmar, France).

\section{Amplification of DNA}

PCR primers to amplify exons using the published genome sequence http://www.cns.fr/externe/English/corps_anglais.html[30] were designed (Table 2). Genomic DNA was amplified by PCR using the following conditions: 10 ng of DNA template, $1 \times$ PCR Buffer (Invitrogen), $1.5 \mathrm{mM} \mathrm{MgCl} 2,200 \mu \mathrm{M}$ each dNTP (Invitrogen), $0.2 \mu \mathrm{M}$ each primer, 1.25 Unit Platinum ${ }^{\bullet}$ Taq DNA Polymerase (Invitrogen) and milli- $\mathrm{Q}^{\circ}$ water to a final volume of $25 \mu \mathrm{l}$. PCR reactions were performed using a $5 \mathrm{~min}$ initial denaturation/activation step, followed by 35 or 40 cycles at $94^{\circ} \mathrm{C}$ for $45 \mathrm{~s}$, Tm for $1 \mathrm{~min}$, and $72^{\circ} \mathrm{C}$ for $1 \mathrm{~min}$ per $\mathrm{Kb}$, with a final extension step of $10 \mathrm{~min}$ at $72^{\circ} \mathrm{C}$. PCR products were assessed by electrophoresis in $1.5 \%$ agarose gels and visualized by ethidium bromide staining. 


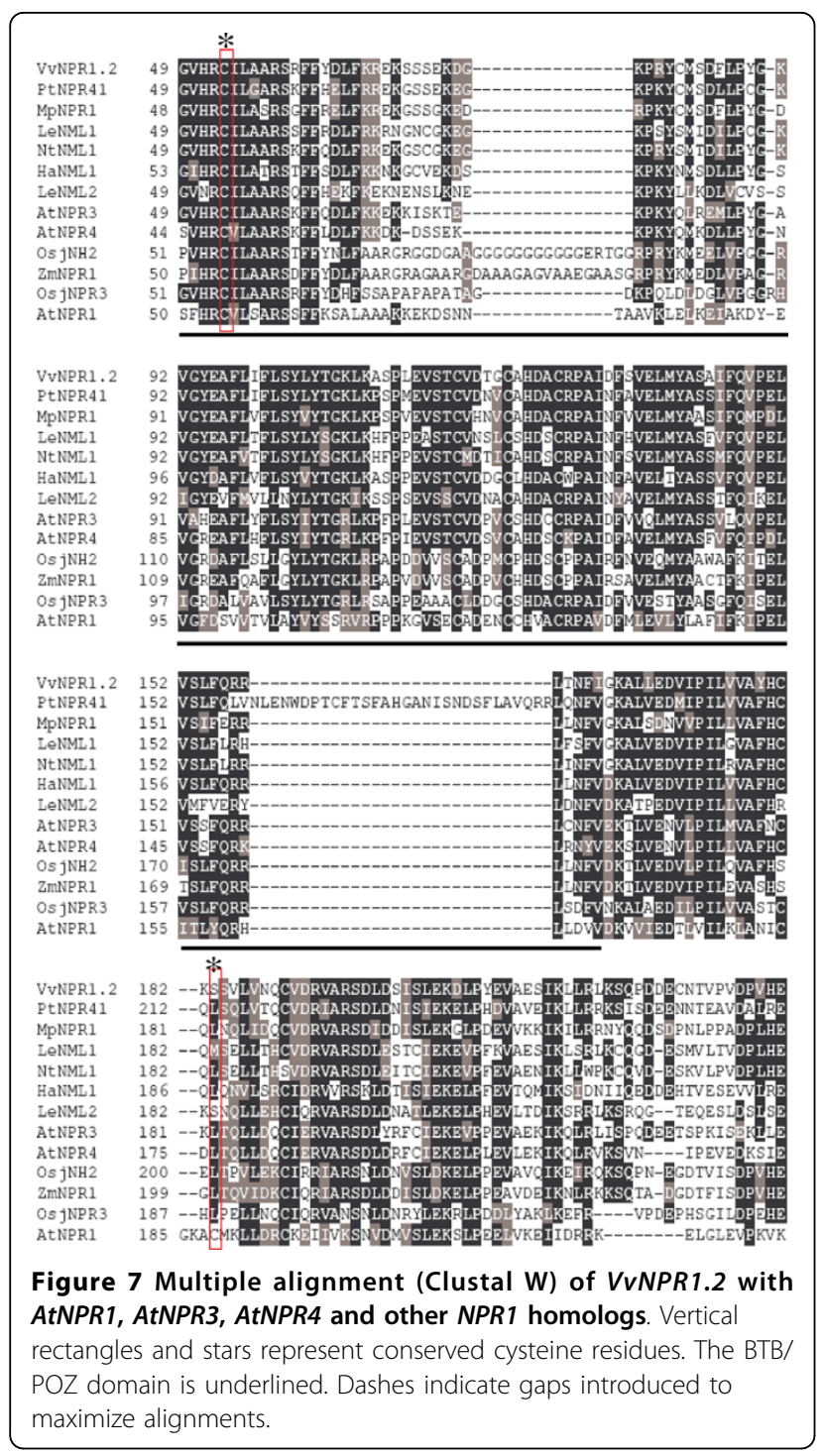

\section{Cloning gene-specific PCR fragments}

When polymorphism appeared after the first sequencing reaction, the PCR products were ligated into the pCR2.1 vector (Original TA Cloning Kit, Invitrogen) according to the manufacturer's instructions. Ligation mixtures were incubated overnight at $14^{\circ} \mathrm{C}$ to obtain the maximum number of transformants. Ligation products were transformed into competent E.coli bacteria cells (In $\alpha F^{\prime}$ ) using a 90 second heat-shock at $42^{\circ} \mathrm{C}$. The bacterial cells were spread onto LB agar plates containing ampicillin $(100 \mu \mathrm{g} / \mathrm{ml})$ (Sigma) and X-Gal $(40 \mu \mathrm{g} / \mathrm{ml})$ (Euromedex).

Plasmid minipreps were performed by the alkaline lysis method [49]. The PCR fragments in the vectors were sequenced by Genoscreen (Lille, France) using M13 and M13 rev primers.

\section{Polymorphism detection methods}

A PCR-based strategy with primers designed on exons amplifying successfully NPR1 gene fragments was used. The sequencing reaction can produce one (homozygote) or two (heterozygote) peaks depending on the genotype for each nucleotide. DNA sequences and the complete protein sequences of members of the NPR1 gene family were aligned using Vector NTI and Bioedit software. Phylogenetic trees were produced using the ClustalW web site http://align.genome.jp/ and the Phylo_win program using the neighbour-joining method [50]. The NPR1 sequences (Table 1) from other species, available in the NCBI GenBank http://www.ncbi.nlm.nih.gov/, were included in the sequence analysis for comparison. The Web-based SMART program was used to predict the $\mathrm{BTB} / \mathrm{POZ}$ domains and to confirm the localization of ankyrin repeats for each protein. Percentage of SNP corresponds to the ratio of number of modified nucleotides to total number of nucleotides for each exon. To examine the evolutionary pressures acting on the NPR1.1 and NPR1.2 genes, the ratio of nonsynonymous (replacement) substitutions to synonymous (silent) nucleotide substitutions was determined [51-53]. Generally, values larger than 1 indicate sequence diversification. Instead, values smaller than or equal to 1 are indicative, respectively, of sequence conservation or random mutagenesis.

\section{Additional bioinformatics databases}

The ESTAP software from Expressed Sequence Tag (EST) projects http://staff.vbi.vt.edu/estap/ was also used to identify NPR1 sequences. Phylogenetic trees were produced using the ClustalW Web site http://www.ebi. ac.uk/Tools/clustalw/index.html. Predicted amino acid sequences were generated using the DNA sequence translate tools EXPASY http://www.expasy.ch/tools/dna. html.

\section{Reviewers' reports}

\section{Reviewer 1: Fyodor Kondrashov, Centre for Genomic Regulation, Barcelona, Spain}

This manuscript suffers from conceptual flaws that renders it incomprehensible and misleading: the difference between mutations, polymorphisms and substitutions is obscured to a degree that I believe in the current form makes the analysis almost meaningless.

The authors determine the sequence of a duplicated orthologs of a NPR1 gene found in Arhabidopsis in several different species and strains of the Vitaceae family. The differences between the obtained sequences the authors interchangeably call "polymorphisms", "substitutions", "modifications" and "mutations". I can only assume that the authors have sequenced several individuals from each species or strain, since the title refers to polymorphisms. 
Table 2 Sequence of primer derived from line 40024 (Genoscope Vitis Genome Browser) to amplify the exons of VVNPR1.1 and VvNPR1.2

\begin{tabular}{|c|c|c|c|}
\hline Gene & Forward primers $\left(5^{\prime}->3^{\prime}\right)$ & Reverse primers $\left(5^{\prime}->3^{\prime}\right)$ & Amplified size (bp) \\
\hline \multirow[t]{4}{*}{ VVNPR1.1 } & ATGGACTACAGAGCTGCTC & CTGATAAAGGCCGACCAAT & 531 \\
\hline & AGACGCCTGATGGACATTC & CTCTATTTTCCTTGAGGTACAACAG & 748 \\
\hline & TTGGACTAGCAAAACTTCTATTCC & CAGTTTTGGACAGTGCTCTTAGCC & 204 \\
\hline & TGGACCTTGGGAAACGCTTIT & TTACTTCTTGCAAGAGAGTCTA & 272 \\
\hline \multirow[t]{4}{*}{ VVNPR1.2 } & ATGGCCAATTCAGCTGAGC & CTGAAAAAGTGAGACCAGCTCTGGTA & 549 \\
\hline & CGGCGTCTTACCAACT & CTCTATTITCCAGGTACAG & 754 \\
\hline & TGGCATTTGCACGATTATTCTTCC & CTGTTITCACAAGGGCATTCATCCTTGAACG & 198 \\
\hline & TGGAGATGGGTCGACGC & TCATAATTITCTAGCCTTGTGAC & 263 \\
\hline
\end{tabular}

However, I did not find a statement of how many individuals were sequenced for each species/strain, or whether or not substitutions where included in the analysis. The authors state that "The NPR1 sequences (Table 1) from other species, [...], were included in the sequence analysis for comparison." What kind of comparison? Is the data really a mix of polymorphisms and substitutions? Such constant confusion between mutational, polymorphism and marco-evolutionary levels provides a huge barrier to comprehension of the results.

Another example: that authors claim that " $[\mathrm{Ka} / \mathrm{Ks}]$ values smaller than or equal to 1 are indicative, respectively, of sequence conservation or random mutagenesis." Actually, $\mathrm{Ka} / \mathrm{Ks}$ of any value can be achieved by random mutagenesis! Unfortunately, there are other, equally frustrating, examples. Before the authors can make a clear distinction between mutations (instantaneous products of mutagenesis), polymorphisms (segregating alleles in a population) and substitutions (sequence differences between homologs in different species or strains) and make it clear to the reader what kind of data they are using the manuscript will remain fatally flawed.

In addition, once the authors can distinguish between these three concepts the data analysis can be expanded to include a combination of phylogenetic and population genetic analyses, broadening the overall ability of the authors to infer the kinds of selection acting in these genes.

A minor issue that arises from the same misconception. The authors spend some time discussing the possible functional implications of different nonsynonymous and nonsense "mutations". All of these functional implications are a mute point if these are deleterious segregating polymorphisms. The functional implications are justified if the authors mean substitutions.

Author's response: The manuscript was improved in response to these observations in particular to make it more comprehensible.

Pages 11 and 12, words "mutations" and "polymorphism" were used by Bakker et al. (2008).
In the last paragraph before "Functional hypothesis [...]", the term "mutations" was used because it is a general conclusion.

We have sequenced a pool of three individuals for each species. Each PCR products was sequenced once. When polymorphism appeared after the first sequencing reaction, the PCR products were ligated into a vector and sequenced six times to generate the two polymorphic alleles, separately. We estimated that this pool is sufficient to represent the whole species studied because grapevine is multiplicated by vegetative propagation. Moreover, our reference 40024 line was also sequenced according to the same procedure, compared to the sequence available on the Genoscope database and no difference was observed. If an allele was identical to our reference but the other one was different, we took account to the polymorphic allele to consider a maximum diversity.

The sentence "The NPR1 sequences (Table 1) from other species [...], were included in the sequence analysis for comparison." refers to Figure 2. The aim of this study was to place our two genes in a set of gene described as NPR1. We used the raw sequence of 40024 line available on the Genoscope database to make our comparison without introducing polymorphisms or substitutions.

We have reduced the functional hypothesis part.

Second review of Bergeault et al. "Low level of polymorphism in two putative orthologs of NPR1 genes in the Viraceae family".

While significantly improved from the last version, I still think that the manuscript suffers from conceptual inconsistencies. Also, now that the results are clearer to me I do not find them interesting or revealing.

The content: The authors show that two paralogs that have a $43 \%$ identity are under negative selection by comparing the density of nonsynonymous and nonsynonymous polymorphisms. This is hardly surprising and I am not sure why the authors think that such a result should be published. Any theory of gene duplications will confirm that nothing but negative selection is expected for such distant paralogs. 
The approach: On the other hand, the authors have the right approach to study the functional impact of the functional impact of the origin of gene duplication, which is one of the least understood part of gene duplication evolution. If the paralogs were $99 \%$ identical than the results would have shown that the origin of a new function occurred quickly, or that the gene duplication itself was adaptive. Many studies of such sort should be undertaken, but this analysis does not mean very much with distant paralogs.

The language: Another unfortunate aspect of this manuscript is that it is littered with terminological inconsistencies. For example the authors say "To examine the evolutionary pressures acting on the NPR1.1 and NPR1.2, the ratio of nonsynonymous (replacement) to synonymous (silent substitution) nucleotides was determined." Clearly, the word "nucleotides" should be either "substitutions" or "polymorphisms". Another such misconception is the claim that $\mathrm{Kn} / \mathrm{Ks}<1$ can signify a recent selective sweep. I disagree: the only other thing it can signify besides negative selection is different mutation rates of synonymous and nonsynoymous sites. Even more unfortunately, is that the authors really mean $\mathrm{Pn} /$ Ps (for polymorphisms, not substitutions) throughout the manuscript and use "substitutions" (which are fixed differences) instead of "polymorphisms" (which are still segregating in the population). Also, instead of using "accessions" some other term, for example "strain" should be used: one cannot extract DNA from an accession.

Author's response: The manuscript was improved in response to these observations in particular to "recent selective sweep" where we are agreeing with Dr Kondrashov. This sentence was suppressed.

The "accession" is frequently used in wine-growing. This term indicates a grape variety, a variety or a clone.

\section{Reviewer 2: Purificación López-García, Université Paris- Sud, Paris, France}

Review of the article "Low level of polymorphism in two putative orthologs of NPR1 genes in the Vitaceae family by Bergeault et al., submitted to Biology Direct. Bergeault et al. identify two homologues of Arabidopsis NPR1 genes, known to be involved in general systemic resistance against pathogens or herbivores, in the genome of the grapevine Vitis vinifera. They subsequently design specific primers and amplify the corresponding genes from various grapevine cultivars. The analysis of those genes show a low level of polymorphism and, based on a ratio of synonymous versus non-synonymous substitutions lower than 1 , the authors conclude that these genes are under purifying selection. Overall, the work is clear and appears well conducted. However, I think that the structure and writing of the manuscript may be improved. A few suggestions follow.

In particular, there are many figures, some of which could be eliminated without loss of essential information. This is the case of figure 6 showing the stop codon region in NPR1.1. As an additional suggestion, figure 1 and 4 could be merged together in a composite figure showing as an inset the NPR1.1 BTB/POZ domain region with the polymorphisms identified. I also believe that figure 8 , showing the different cultivars analyzed, should appear as figure 1 at the beginning of the results section, since these are the cultivars subsequent work is about. Otherwise, placing it at the end of the manuscript with only a brief mention in the Methods section would make it dispensable.

The long discussion about the potential functions of NPR1 genes in $V$. vinifera is rather speculative in the absence of actual functional data and could be significantly shortened.

Bergeault et al. observed that "in six $V$. vinifera cultivars SNP rate to introns was not significantly different to exons". Why? Could this suggest that the low SNP observed is not (at least totally) due to purifying selection but to other kind of constraint acting on that particular genomic region?

Minor comments:

- First paragraph of Background. Some references should be added. Readers may be not familiar with $V$. vinifera and their general genomic characteristics.

- Page 12, last line before "Functional hypothesis...". Sexual instead of sexuel.

- Page 15, "high homology values". This expression is incorrect. Homology is an all-or-nothing quality. Either two genes are homologous (derive from a common ancestor) or they are not. "High similarity or identity values" would be more appropriate.

Author's response: The manuscript was improved in response to these very useful comments. In answer to the question concerning the SNP rate to introns, it is not significantly different to exons and this for the 3 introns which compose each gene. We suppose indeed that it is due to purifying selection since it is observed in 3 introns in six $\mathrm{V}$. vinifera.

For the incorrect expression in the minor comments, this sentence was suppressed.

\section{Reviewer 3: George V. Shpakovski Shemyakin- Ovchinnikov Institute of Bioorganic Chemistry, Russian Academy of Sciences, Moscow, Russia}

This is my second review of this manuscript (my previous comments were addressed by the authors in their new manuscript submission). The authors report the results of an experimental (PCR-based) and computational study of 
NPR1 [Nonexpressor of Pathogenesis Related 1]-like genes' polymorphism in different species of the Vitaceae family. Grapevine is subjected to numerous stresses (both enviromental and pathogeneous), and new knowledge on its defence mechanisms (NPR1 gene is one of the main component of systemic acquired resistance [SAR] in plants) certainly will be beneficial both for scientific community and for human society in general. The main finding of the manuscript is the fact that family of NPR genes in Vitis vinifera and probably in all other plants consists of at least 3 separate branches. These 3 subfamilies of NPR genes in plants exemplified in Arabidopsis thaliana by AtNPR1, AtNPR3 and AtNPR5 (BOP) genes, respectively. Analysis of nucleotide polymorphisms in two NPR1-like genes from fifteen accessions belonging to the Vitaceae family indicate that the genes are under purifying selection, but the AtNPR1 ortholog (VvNRP1.1) is more polymorphic. A tentative hypothesis of authors about two types (positive and negative) of regulation by different subfamilies of NPR1genes although is interesting, but certainly needs some further experimental support. The revised version of the manuscript takes the suggestions that I previously made into account. The changes in the revised manuscript and the new title help to clarify the aim of the manuscript considerably. In my opinion, it would be better to re-name Vitis genes described by the authors on VvNRP1, VvNRP3 and $V v N R P 5$ instead of $V v N R P 1.1, V v N R P 1.2$ and $V v B O P$ at it is in the text. The manuscript might need some additional editing and proofreading.

Author's response: We are grateful to Dr Shpakovski for his comments and notice very judicious. Indeed, the hypothesis about their functions is essentially based on a work on literature. But, we think that it was interesting to discuss the two types of SAR regulation. Moreover, we indicate in the manuscript "Therefore, phylogenetic analysis is not sufficient to predict a positive or negative control of defence responses for VvNPR1.2."

With regard to re-name Vitis genes, another classification would make confusion. For example, where are VvNPR2 and VvNPR4? Moreover, we have at present no data concerning VvNPR1.2 which would act as a negative regulator of SAR and it would be premature to rename it, VvNPR3.

\begin{abstract}
Abbreviations
NPR1: non expressor of PR 1; SA: salicylic acid; JA: jasmonic acid; PR: pathogenesis-related; SAR: systemic acquired resistance; ISR: induced systemic resistance; $\mathrm{BTB} / \mathrm{POZ}$ : broad complex, tramtrack and bric a brac/pox virus and zinc finger; ARD: ankyrin repeat domain; NLS: nuclear localization signal.
\end{abstract}

\section{Acknowledgements}

This research was supported by the "Université de Haute Alsace" and by a doctoral fellowship from the "Région Alsace" to KB. We are grateful to Frederique Pelsy (INRA, Colmar, France) for providing the DNA of Ampelopsis japonica, Muscadinia rotundifolia, Parthenocissus quinquefolia, American Vitis species (arizonica, labrusca Isabelle, rupestris du Lot, aestivalis and cinerea), Vitis vinifera cultivars (Gouais blanc, Muscat reine des vignes, Cabernet Sauvignon, Riesling, Pinot noir), and to Valerie Hofstetter (Department of Ecology, University of Lausanne, Switzerland) for comments and suggestions which helped to improve the quality of this manuscript. Special thanks to Laetitia Chartrain (John Innes Centre, Norwich, United Kingdom) for helpful English corrections.

\section{Author details}

${ }^{1}$ Laboratoire Vigne, Biotechnologies \& Environnement, Université de Haute Alsace, 33 rue de Herrlisheim, 68000 Colmar, France. ${ }^{2}$ Laboratoire de Génétique et Amélioration de la Vigne, INRA et Université de Strasbourg (UMR1131), 28 rue de Herrlisheim, 68000 Colmar, France.

\section{Authors' contributions}

$\mathrm{KB}$ carried out all the experiments, alignment and comparison of the sequences, phylogenetic analyses and drafted the manuscript. CB and BW initiated and conceived the study, have done general supervision and coordination and corrected the manuscript. DM participated in the design of the study and helped to organize the manuscript. All authors read and approved the final manuscript.

\section{Competing interests}

The authors declare that they have no competing interests.

Received: 2 April 2009

Accepted: 5 February 2010 Published: 5 February 2010

\section{References}

1. Alleweldt G, Possingham JV: Progress in grapevine breeding. Theoretical and Applied Genetics 1988, 75(5):669-673.

2. Galet P: Précis de viticulture. Imprimerie Déhan, Montpellier, France 1993.

3. Organisation international de la vigne et du vin: Statistiques vitivinicoles mondiales.http://news.reseau-concept.net/images/oiv/client/ Commentaire_Statistiques_2005_FR.pdf.

4. Kunkel BN, Brooks DM: Cross talk between signaling pathways in pathogen defense. Curr Opin Plant Biol 2002, 5(4):325-331.

5. Cao H, Bowling SA, Gordon AS, Dong X: Characterization of an Arabidopsis mutant that is nonresponsive to inducers of systemic acquired resistance. Plant Cell 1994, 6(11):1583-1592.

6. Cao H, Glazebrook J, Clarke JD, Volko S, Dong X: The Arabidopsis NPR1 gene that controls systemic acquired resistance encodes a novel protein containing ankyrin repeats. Cell 1997, 88(1):57-63.

7. Ryals JA, Neuenschwander UH, Willits MG, Molina A, Steiner HY, Hunt MD: Systemic Acquired Resistance. Plant Cell 1996, 8(10):1809-1819.

8. Dong X: NPR1, all things considered. Curr Opin Plant Biol 2004, 7(5):547-552.

9. Friedrich L, Lawton K, Ruess W, Masner P, Specker N, Gut Rella M, Meier B, Dincher S, Staub T, Uknes S, Metraux J-P, Kessmann H, Ryals J: A benzothiadiazole derivative induces systemic acquired resistance in tobacco. Plant J 1996, 10(1):61-70.

10. Sticher L, Mauch-Mani B, Métraux JP: Systemic acquired resistance. Annu Rev Phytopathol 1997, 35(1):235-270

11. van Wees SC, de Swart EA, van Pelt JA, van Loon LC, Pieterse CM: Enhancement of induced disease resistance by simultaneous activation of salicylate- and jasmonate-dependent defense pathways in Arabidopsis thaliana. Proc Natl Acad Sci USA 2000, 97(15):8711-8716.

12. Spoel SH, Koornneef A, Claessens SMC, Korzelius JP, Van Pelt JA, Mueller MJ, Buchala AJ, Métraux J-P, Brown R, Kazan K, Van Loon LC, Dong X, Pieterse CM: NPR1 modulates cross-talk between salicylate- and jasmonate-dependent defense pathways through a novel function in the cytosol. Plant Cell 2003, 15(3):760-770.

13. Despres C, DeLong C, Glaze S, Liu E, Fobert PR: The Arabidopsis NPR1/ NIM1 protein enhances the DNA binding activity of a subgroup of the TGA family of bZIP transcription factors. Plant Cell 2000, 12(2):279-290.

14. Despres C, Chubak C, Rochon A, Clark R, Bethune T, Desveaux D, Fobert PR: The Arabidopsis NPR1 disease resistance protein is a novel cofactor that confers redox regulation of DNA binding activity to the basic domain/ leucine zipper transcription factor TGA1. Plant Cell 2003, 15(9):2181-2191.

15. Mou Z, Fan W, Dong $X$ : Inducers of plant systemic acquired resistance regulate NPR1 function through redox changes. Cell 2003, 113(7):935-944. 
16. Liu G, Holub EB, Alonso JM, Ecker JR, Fobert PR: An Arabidopsis NPR1-like gene, NPR4, is required for disease resistance. Plant J 2005, 41(2):304-318.

17. Chern M-S, Fitzgerald HA, Yadav RC, Canlas PE, Dong X, Ronald PC: Evidence for a disease-resistance pathway in rice similar to the NPR1mediated signaling pathway in Arabidopsis. Plant J 2001, 27(2):101-113.

18. Chern M, Canlas PE, Fitzgerald HA, Ronald PC: Rice NRR, a negative regulator of disease resistance, interacts with Arabidopsis NPR1 and rice NH1. Plant J 2005, 43(5):623-635.

19. Meur G, Budatha M, Dutta Gupta A, Prakash S, Kirti PB: Differential induction of NPR1 during defense responses in Brassica juncea. Physiol Mol Plant Pathol 2006, 68(4-6):128-137.

20. Malnoy M, Jin Q, Borejsza-Wysocka EE, He SY, Aldwinckle HS: Overexpression of the apple MpNPR1 gene confers increased disease resistance in Malus $\times$ domestica. Mol Plant Microbe Interact 2007, 20(12):1568-1580.

21. Zhang Y, Wang X, Cheng C, Gao Q, Liu J, Guo X: Molecular cloning and characterization of GhNPR1, a gene implicated in pathogen responses from cotton (Gossypium hirsutum L.). Biosci Rep 2008, 28(1):7-14.

22. Cao H, Li X, Dong X: Generation of broad-spectrum disease resistance by overexpression of an essential regulatory gene in systemic acquired resistance. Proc Natl Acad Sci USA 1998, 95(11):6531-6536.

23. Chern M, Fitzgerald HA, Canlas PE, Navarre DA, Ronald PC: Overexpression of a rice NPR1 homolog leads to constitutive activation of defense response and hypersensitivity to light. Mol Plant Microbe Interact 2005 18(6):511-520.

24. Fitzgerald HA, Chern M-S, Navarre R, Ronald PC: Overexpression of (At) $N P R 1$ in rice leads to a $\mathrm{BTH}$ - and environment-induced lesion-mimic/cell death phenotype. Mol Plant Microbe Interact 2004, 17(2):140-151.

25. Friedrich $L$, Lawton $K$, Dietrich $R$, Willits $M$, Cade R, Ryals J: NIM1 overexpression in Arabidopsis potentiates plant disease resistance and results in enhanced effectiveness of fungicides. Mol Plant Microbe Interact 2001, 14(9):1114-1124.

26. Lin WC, Lu CF, Wu JW, Cheng ML, Lin YM, Yang NS, Black L, Green SK, Wang JF, Cheng CP: Transgenic tomato plants expressing the Arabidopsis NPR1 gene display enhanced resistance to a spectrum of fungal and bacterial diseases. Transgenic Res 2004, 13(6):567-581.

27. Makandar R, Essig JS, Schapaugh MA, Trick HN, Shah J: Genetically engineered resistance to Fusarium head blight in wheat by expression of Arabidopsis NPR1. Mol Plant Microbe Interact 2006, 19(2):123-129.

28. Buckler ES, Thornsberry JM: Plant molecular diversity and applications to genomics. Curr Opin Plant Biol 2002, 5(2):107-111.

29. Troggio M, Malacarne G, Coppola G, Segala C, Cartwright DA, Pindo M, Stefanini M, Mank R, Moroldo M, Morgante M, Grando MS, Velasco R: A dense single-nucleotide polymorphism-based genetic linkage map of grapevine (Vitis vinifera L.) anchoring Pinot Noir bacterial artificial chromosome contigs. Genetics 2007, 176(4):2637-2650.

30. Jaillon O, Aury JM, Noel B, Policriti A, Clepet C, Casagrande A, Choisne N, Aubourg $S$, Vitulo $N$, Jubin $C$, et al: The grapevine genome sequence suggests ancestral hexaploidization in major angiosperm phyla. Nature 2007, 449(7161):463-467

31. Velasco R, Zharkikh A, Troggio M, Cartwright DA, Cestaro A, Pruss D, Pindo M, Fitzgerald LM, Vezzulli $S$, Reid J, et al: A high quality draft consensus sequence of the genome of a heterozygous grapevine variety. PLOS ONE 2007, 2(12):e1326.

32. Le Henanff G, Heitz T, Mestre P, Mutterer J, Walter B, Chong J: Characterization of Vitis vinifera NPR1 homologs involved in the regulation of Pathogenesis-Related gene expression. BMC Plant Biology 2009, 9(1):54.

33. Kim HS, Delaney TP: Over-expression of TGA5, which encodes a bZIP transcription factor that interacts with NIM1/NPR1, confers SARindependent resistance in Arabidopsis thaliana to Peronospora parasitica. Plant J 2002, 32(2):151-163.

34. Zhang Y, Cheng YT, Qu N, Zhao Q, Bi D, Li X: Negative regulation of defense responses in Arabidopsis by two NPR1 paralogs. Plant J 2006, 48(5):647-656.

35. Zhang Y, Fan W, Kinkema M, Li X, Dong X: Interaction of NPR1 with basic leucine zipper protein transcription factors that bind sequences required for salicylic acid induction of the PR-1 gene. Proc Natl Acad Sci USA 1999, 96(11):6523-6528.

36. Zhou JM, Trifa Y, Silva H, Pontier D, Lam E, Shah J, Klessig DF: NPR1 differentially interacts with members of the TGA/OBF family of transcription factors that bind an element of the $P R-1$ gene required for induction by salicylic acid. Mol Plant Microbe Interact 2000, 13(2):191-202.

37. Hepworth SR, Zhang Y, McKim S, Li X, Haughn GW: BLADE-ON-PETIOLEdependent signaling controls leaf and floral patterning in Arabidopsis. Plant Cell 2005, 17(5):1434-1448.

38. Endah R, Beyene G, Kiggundu A, Berg van den N, Schlüter U, Kunert K, Chikwamba R: Elicitor and Fusarium-induced expression of NPR1-like genes in banana. Plant Physiol Biochem 2008, 46(11):1007-1014.

39. Zwicker S, Mast S, Stos V, Pfitzner AJP, Pfitzner UM: Tobacco NIMIN2 proteins control $P R$ gene induction through transient repression early in systemic acquired resistance. Mol Plant Pathol 2007, 8(4):385-400.

40. Ohyanagi $H$, Tanaka $T$, Sakai H, Shigemoto $Y$, Yamaguchi $K$, Habara T, Fujii $Y$, Antonio BA, Nagamura Y, Imanishi T, Ikeo K, Itoh T, Gojobori T, Sasaki T: The Rice Annotation Project Database (RAP-DB): hub for Oryza sativa ssp. japonica genome information. Nucl Acids Res 2006, 34(suppl_1):D741-744.

41. Galet P: Recherches sur les méthodes d'identification et de classification des Vitacées des zones tempérées. PhD dissertation University of Montpellier, France 1967

42. Bardwell VJ, Treisman R: The POZ domain: a conserved protein-protein interaction motif. Genes Dev 1994, 8(14):1664-1677.

43. Kadowaki T, Kadowaki H, Taylor SI: A nonsense mutation causing decreased levels of insulin receptor mRNA: detection by a simplified technique for direct sequencing of genomic DNA amplified by the polymerase chain reaction. Proc Natl Acad Sci USA 1990, 87(2):658-662.

44. Bakker EG, Traw MB, Toomajian C, Kreitman ME, Bergelson J: Low levels of polymorphism in genes that control the activation of defense response in Arabidopsis thaliana. Genetics 2008, 2032-2043.

45. Caldwell KS, Michelmore RW: Arabidopsis thaliana genes encoding defense signaling and recognition proteins exhibit contrasting evolutionary dynamics. Genetics 2009, 181(2):671-684.

46. Potlakayala SD, DeLong C, Sharpe A, Fobert PR: Conservation of NONEXPRESSOR OF PATHOGENESIS-RELATED GENES1 function between Arabidopsis thaliana and Brassica napus. Physiol Mol Plant Pathol 2007, 71(4-6):174-183.

47. Yuan Y, Zhong S, Li Q, Zhu Z, Lou Y, Wang L, Wang J, Wang M, Li Q, Yang D, He Z: Functional analysis of rice NPR1-like genes reveals that OsNPR1/NH1 is the rice orthologue conferring disease resistance with enhanced herbivore susceptibility. Plant Biotechnol J 2007, 5(2):313-324.

48. Bronner A, Oliveira J: Creation et étude de lignées chez le Pinot Noir (Vitis vinifera L.). J Int Sci Vigne Vin 1991, 25:133-148.

49. Sambrook J, Russell D: Molecular cloning: A laboratory manual. Cold Spring Harbor Laboratory 2001.

50. Galtier N, Gouy M, Gautier C: SEAVIEW and PHYLO_WIN: two graphic tools for sequence alignment and molecular phylogeny. Comput Appl Biosci 1996, 12(6):543-548.

51. Nei M, Gojobori T: Simple methods for estimating the numbers of synonymous and nonsynonymous nucleotide substitutions. Mol Biol Evol 1986, 3(5):418-426.

52. Kimura M: Preponderance of synonymous changes as evidence for the neutral theory of molecular evolution. Nature 1977, 267(5608):275-276.

53. Miyata T, Yasunaga T: Molecular evolution of mRNA: A method for estimating evolutionary rates of synonymous and amino acid substitutions from homologous nucleotide sequences and its application. J Mol Evol 1980, 16:23-36.

doi:10.1186/1745-6150-5-9

Cite this article as: Bergeault et al:: Low level of polymorphism in two putative NPR1 homologs in the Vitaceae family. Biology Direct 2010 5:9. 